DOI: 10.12731/2658-6649-2020-12-4-84-103

УДК 616.12.127: 616-056.52

\title{
СТРУКТУРНО-ФУНКЦИОНАЛЬНОЕ СОСТОЯНИЕ МИОКАРДА И ТИПЫ ГЕМОДИНАМИКИ У МУЖЧИН С АРТЕРИАЛЬНОЙ ГИПЕРТОНИЕЙ РАЗЛИЧНЫХ КОНСТИТУЦИОНАЛЬНЫХ ТИПОВ
}

\section{Яскевич Р.А., Повшедная О.Н., Москаленко О.Л.}

Цель. Изучение структурно-функциионального состояния миокарда и типов гемодинамики у мужчин с АГ различных конституциональных muпов.

Материальи и методы. Обследовано 89 мужчин в возрасте от 20 до 60 лет. Использовалась стандартная методика антропометрического исследования с последующим определением конституциональных типов, а также определение типов гемодинамики по данным ультразвукового исследования сердия.

Результаты. В ходе проведённого исследования установлено, что как среди больных АГ, так и среди лиц без АГ, эукинетический и гиперкинетический типы гемодинамики встречаются чаще по сравнению с гипокинетическим типом. При изучении частоты встречаемости типов гемодинамики у больных АГ с различными соматотипами не получено статистически значимо различий между группами соматотипов, в то время как в группе контроля количество лиц с мускульным соматотипом была статистически значимо выше при эукинетическомо типа, и ниже при гиперкинетическом типе в сравнении сравнению с груднылм и брюшным соматотипами. При сравнении структурно-функциональных показателей миокарда у больных АГ разных соматотипов можно отметить, что величина фракции выброса и фракции сокращения у больных АГ неопределенного соматотипа были наименьшими и статистически значимо более низкими по сравнению с грудным типом телосложения $(p<0,01)$, а у лиц с АГ грудного соматотипа статистически значимо более высокими по сравнению с брюшнылм конституцчиональным типом $(p<0,05)$.

Заключение. Для лиц с АГ грудного соматотипа характерны более благоприятные значения некоторых структурно-функциональных пока- 
зателей состояния миокарда, в сравнении с брюшным и неопределенным типами конституции.

Ключевые слова: артериальная гипертония; соматотип; структурно-функииональное состояние миокарда; тип гемодинамики.

\title{
STRUCTURAL AND FUNCTIONAL STATE OF THE MYOCARDIALAND TYPES OF HEMODYNAMICS IN MEN WITH ARTERIAL HYPERTENSION OF DIFFERENT CONSTITUTIONAL TYPES
}

\author{
Yaskevich R.A., Povshednaya O.N., Moskalenko O.L.
}

The purpose of the study. Study of the structural and functional state of the myocardium and types of hemodynamics in men with hypertension of various constitutional types.

Materials and methods. 89 men aged from 20 to 60 years were examined. The standard technique of anthropometric research used, followed by determination of constitutional types, as well as determination of the types of hemodynamics according to the data of ultrasound examination of the heart.

Results. In the course of the study, it found that both among patients with arterial hypertension and among those without arterial hypertension, eukinetic and hyperkinetic types of hemodynamics are more common in comparison with the hypokinetic type. When studying the frequency of occurrence of types of hemodynamics in hypertensive patients with different somatotypes, no statistically significant differences obtained between groups of somatotypes. In the control group, the number of persons with a muscular somatotype was statistically significantly higher in the eukinetic type and lower in the hyperkinetic type in comparison with the thoracic and abdominal somatotypes. When comparing the structural and functional parameters of the myocardium in patients with arterial hypertension of different somatotypes, it can be noted that the value of the ejection fraction and reduction fraction in patients with arterial hypertension of an undefined somatotype were the smallest. Also statistically significantly lower in comparison with the pectoral body type $(p<0,01)$. In persons with arterial hypertension of the thoracic somatotype, they were statistically significantly higher than in the abdominal constitutional type $(p<0,05)$.

Conclusion. Individuals with hypertension of the thoracic somatotype characterized by more favorable values of some structural and functional indicators 
of the state of the myocardium, in comparison with the abdominal and indefinite types of constitution.

Keywords: arterial hypertension; somatotype; structural and functional state of the myocardium; type of hemodynamics.

\section{Введение}

Заболевания сердечно-сосудистой системы как причина инвалидизации и летальности среди других нозологических форм занимают одно из первых мест не только во всем мире [Britton K.A., Massaro J.M., Murabito J.M. et al. Body fat distribution, incident cardiovascular disease, cancer, and allcause mortality // J. Am. Coll. Cardiol. 2013. Vol. 62, N.10. P. 921-925., Nichols M., Townsend N., Scarborough P., Rayner M. Cardiovascular disease in Europe: epidemiological update // Eur. Heart J. 2013. Vol.34. P. 3028-3034., Selvaraj S., Martinez E.E., Aguilar F.G. et al. Association of central adiposity with adverse cardiac mechanics: findings from the HyperGEN Study // Circ. Cardiovasc. Imaging. 2016. Vol. 9, N 6. P. e004396., Williams B., Mancia G., Spiering W. et al; ESC Scientific Document Group. 2018 ESC/ESH Guidelines for the management of arterial hypertension. The Task Force for the management of arterial hypertension of the European Society of Cardiology (ESC) and the European Society of Hypertension (ESH) // European Heart Journal. 2018. Vol. 39, N 33. Р. 3021-104.], но и в России [Поликарпов Л.С., Хамнагадаев И.И., Яскевич Р.А., Деревянных Е.В. Артериальная гипертония (распространенность, профилактика, адаптация и реадаптация к различным экологическим условиям). Красноярск: КрасГМУ, 2010. 289 c., Polikarpov L.S., Yaskevich R.A., Derevyannich E.V. et al. Readaptation of patients with arterial hypertension long-term residents of the Far North to new climatic conditions // International Journal of Circumpolar Health. 2012. Vol. 72, S 1. P. 337-339.]. Между различными формами сердечно-сосудистой патологии, артериальная гипертония (АГ) привлекает всеобщее внимание, которое обусловлено её высокой популяционной частотой, негативным влиянием на состояние здоровья, работоспособность и продолжительность жизни населения [Давыдов Е.Л., Ульянова И.О. Медико-социальные аспекты больных артериальной гипертонией в пожилом возрасте // Клиническая геронтология. 2016. Т. 22, № 9-10. С. 24-25., Деревянных Е.В., Яскевич Р.А., Балашова Н.А. Возрастные особенности приверженности к лечению артериальной гипертонии у мужчин г. Красноярска // Международный журнал прикладных и фундаментальных исследований. 2016. № 6-1. С. 48-52., Поликарпов Л.С., Хамнагадаев И.И., Яскевич Р.А., Деревянных Е.В. Артериальная ги- 
пертония (распространенность, профилактика, адаптация и реадаптация к различным экологическим условиям). Красноярск: КрасГМУ, 2010. 289 c., Polikarpov L.S., Yaskevich R.A., Derevyannich E.V. et al. Readaptation of patients with arterial hypertension long-term residents of the Far North to new climatic conditions // International Journal of Circumpolar Health. 2012. Vol. 72, S 1. P. 337-339.]. В тоже время своевременный контроль факторов риска CС3, на ранней стадии может предотвратить развитие данной патологии [Кедринская А.Г., Куприенко Н.Б., Образцова Г.И., Леонова И.А. Структурные изменения сердца и антропометрические маркеры ремоделирования миокарда при избыточной массе тела и ожирении у детей // Артериальная гипертензия. 2018. Т. 24, № 5. С.570-580, Клеменков А.С., Фурсова Я.Е., Клеменков С.В. и др. Влияние общих пресных ванн и физических тренировок при разной длительности назначения на физическую работоспособность больных стабильной стенокардией с нарушением ритма // Фундаментальные исследования. 2006. № 3. С. 13., Поликарпов Л.С., Хамнагадаев И.И., Яскевич Р.А., Деревянных Е.В. Артериальная гипертония (распространенность, профилактика, адаптация и реадаптация к различным экологическим условиям). Красноярск: КрасГМУ, 2010. 289 с.]. Основной характеристикой АГ является постоянно повышенное артериальное давление (АД). Помимо этого, АГ сопровождается изменением и других гемодинамических параметров, характеризующих кровоток, сосудистое сопротивление, волемический статус, сократительную способность миокарда, эластичность сосудистой стенки и доставку кислорода [Антонов А.А. Гемодинамика при гипертонической болезни // Поликлиника. 2013. № 4-2. С. 36-41., Деревянных Е.В., Яскевич Р.А. Изучение и сравнительный анализ показателей центральной гемодинамики и артериального давления у пожилых мигрантов Крайнего Севера с артериальной гипертензией // Клиническая геронтология. 2017. Т. 23. № 9-10. С. 23-25., Kim N. Y., Hong Y.M., Jung J.W. et al. The relationships of body mass index, waist-toheight ratio, and body fat percentage with blood pressure and its hemodynamic determinants in Korean adolescents: a school-based study // Korean J. Pediatr. 2013. Vol. 56, N 12. Р. 526-533.]. Многочисленные исследования показали, что среди пациентов с АГ существует несколько различных групп, отличающихся друг от друга состоянием гемодинамики [Деревянных Е.В., Яскевич Р.А. Изучение и сравнительный анализ показателей центральной гемодинамики и артериального давления у пожилых мигрантов Крайнего Севера с артериальной гипертензией // Клиническая геронтология. 2017. Т. 23. № 9-10. С. 23-25., Поликарпов Л.С., Хамнагадаев И.И., Яскевич Р.А., 
Деревянных Е.В. Артериальная гипертония (распространенность, профилактика, адаптация и реадаптация к различным экологическим условиям). Красноярск: КрасГМУ, 2010. 289 с., Терегулов Ю.Э. Интегральные показатели центральной гемодинамики у здоровых лиц и пациентов с гипертонической болезнью в зависимости от типа гемодинамики // Практическая медицина. 2012. № 8-2 (64). С. 164-168., Халявкина И.О. Индивидуально-типологические особенности гемодинамики в юношеском возрасте // Журнал фундаментальной медицины и биологии. 2017. №1. С. 38-44.]. Сведения о частоте разных гемодинамических типов существенно различаются [Антонов А.А. Гемодинамика при гипертонической болезни // Поликлиника. 2013. № 4-2. С. 36-41., Деревянных Е.В., Яскевич Р.А. Изучение и сравнительный анализ показателей центральной гемодинамики и артериального давления у пожилых мигрантов Крайнего Севера с артериальной гипертензией // Клиническая геронтология. 2017. Т. 23. № 9-10. С. 23-25.]. Имеющиеся данные о распространенности типов гемодинамики в разных возрастных группах людей, свидетельствуют о преобладании у детей и подростков гиперкинетического, реже - эукинетического типа, часто сменяющегося с повышением возраста, на гипокинетический тип гемодинамики [Халявкина И.О. Индивидуально-типологические особенности гемодинамики в юношеском возрасте // Журнал фундаментальной медицины и биологии. 2017. №1. С. 38-44.].

Индивидуально-типологические особенности человека могут быть маркерами, которые характеризуют особенности клинических проявлений и помогают в прогнозировании развития и тяжести течения тех или иных заболеваний [Деревянных Е.В., Яскевич Р.А., Балашова Н.А. Антропометрические особенности и компонентный состав массы тела у мужчин медицинских работников с артериальной гипертонией // Международный журнал прикладных и фундаментальных исследований. 2016. № 6-2. С. 252-256., Козлов Е.В., Яскевич Р.А., Москаленко О.Л., Кочергина К.Н. Антропометрические особенности и компонентный состав массы тела у мужчин с хронической обструктивной болезнью легких в условиях коморбидности // Siberian Journal of Life Sciences and Agriculture. 2019. T. 11. № 4. С. 56-73., Москаленко О.Л. Характеристика свойств темперамента у юношей-студентов разных соматотипов г. Железногорска // В мире научных открытий. 2015. № 8.1 (68). С. 442-449., Яскевич Р.А., Деревянных Е.В., Балашова Н.А. Использование показателей соматотипирования у мужчин в построении математических моделей прогноза развития артериальной гипертонии // Международный журнал прикладных и фундаментальных 
исследований. 2015. № 1-1. С. 64-69., Яскевич Р.А., Повшедная О.Н., Деревянных Е.В. Нарушения ритма сердца у мужчин, жителей Сибири, с артериальной гипертонией различных конституциональных типов // Успехи современного естествознания. 2015. № 3. С. 127-132.]. Установлено, что определённое внешнее строение тела человека может соответствовать не только определенному внутреннему его строению, но и анатомо-физиологическим особенностям сердца и сосудов [Василькова Т.Н., Баклаева Т.Б., Матаев С.И. Рыбина Ю.А. Влияние различных типов жироотложения на состояние сердечно-сосудистой системы // Сердце: журнал для практикующих врачей. 2014. Т.75, №1. С. 45-49., Никитюк Д.Б., Николенко В.Н., Хайруллин Р.М. и др. Антропометрический метод и клиническая медицина // Журнал анатомии и гистопатологии. 2013. Т. 2, № 2. С. 1014., Шалауров А.В., Кочетова Н.В., Додонова Л.П., Щедрин А.С. Соматотип и основные показатели деятельности сердечно-сосудистой системы в покое и при физической нагрузке // Новости спортивной и медицинской антропологии. М., 1990. Вып. 1. С.163., Яскевич Р.А., Москаленко О.Л. Антропометрические особенности и компонентный состав массы тела у мужчин мигрантов Крайнего Севера с артериальной гипертонией // В мире научных открытий. 2016. № 10 (82). С. 10-34.]. Показано, что разные типы гемодинамики обладают разными адаптационными возможностями и связаны с конституциональными особенностями организма [Никитюк Д. Б., Николенко В.Н., Хайруллин Р.М. и др. Антропометрический метод и клиническая медицина // Журнал анатомии и гистопатологии. 2013. Т. 2 , № 2. С. 10-14.]. Шалауров А.В. с соавт. (1990) выявили связь соматотипа с функциональным состоянием сердечно-сосудистой системы у мужчин, наиболее эффективное функционирование сердечно-сосудистой системы как в покое, так и при нагрузке было отмечено у представителей грудного соматотипа [Шалауров А.В., Кочетова Н.В., Додонова Л.П., Щедрин А.С. Соматотип и основные показатели деятельности сердечно-сосудистой системы в покое и при физической нагрузке // Новости спортивной и медицинской антропологии. М., 1990. Вып. 1. С.163.]. В связи с этим большой интерес представляет изучение взаимосвязи конституциональных особенностей и структурно-функционального состояния миокарда и типов гемодинамики у лиц с АГ.

\section{Цель исследования}

Изучение структурно-функционального состояния миокарда и типов гемодинамики у мужчин с АГ различных конституциональных типов. 


\section{Материалы и методы}

С целью изучения структурно-функционального состояние миокарда и типов гемодинамики у мужчин с АГ различных типов конституции обследованы мужчины проходившие стационарное лечении в кардиологическом отделении клиники Института медицинских проблем Севера г. Красноярска. Обследовано 89 человек мужского пола в возрасте 20-60 лет (средний возраст 44,9 \pm 0,71 лет), из которых обследованных лиц с АГ было 50 человек (средний возраст 45,26 $\pm 0,92$ лет). Контрольную группу составили 39 пациентов с нормальными уровнями АД (средний возраст $44,4 \pm 1,13$ лет). Все участвующие в проводимом исследовании пациенты давали письменное информированное согласие. Исследование проводилось в соответствии с этическими принципами Хельсинкской декларации и было одобрено локальным этическим комитетом.

Использовалась стандартная методика антропометрического исследования с последующим определением конституциональных типов, а также определение вариантов ремоделирования левого желудочка по данным ультразвукового исследования сердца. Эхокардиография проводилась на аппарате «Aloka 1100» с датчиком 2,5 МГц, в М-модальном и двухмерном режиме в стандартных эхокардиографических позициях. Тип центральной гемодинамики определялся с учетом сердечного и ударного индексов, среднего гемодинамического давления и общего периферического сосудистого сопротивления, рассчитанных по стандартным формулам.

Статистический анализ полученных результатов проводилась с использованием программы Statistica 6.0 Статистическую значимость различий между группами при проверке нулевой гипотезы оценивали согласно критерию Манна-Уитни-Вилкоксона. Оценка сравнения качественных показателей проводилась с использованием критерия $\chi^{2}$ (chi-squrae) Пирсона. Критический уровень статистической значимости при проверке нулевой гипотезы принимали при 95\% уровне значимости $(\mathrm{p} \leq 0,05)$.

\section{Результаты и обсуждение}

Проведенное антропометрическое исследование позволило распределить мужчин с АГ и без АГ по конституциональным типам. У мужчин с АГ, чаще определялся брюшной конституциональный тип $-62,0 \%(\mathrm{p}=0,001)$, реже наблюдались лица с неопределенным - 18,0\%, грудным - 10,0\% и мускульным - 10,0\% типами конституции, в то время как у мужчин без АГ чаще, на уровне тенденции, выявлялись лица грудного конситуцио- 
нального типа $-33 \%$, реже мускульного $-25,6 \%$, брюшного $-23,1 \%$ и неопределенного $-17,9 \%$.

При изучении структурно-функциональных показателей миокарда у больных АГ разных соматотипов установлено, что значения фракции выброса (ФВ) и фракции сокращения (ФС) у больных неопределенного соматотипа были наименьшими и статистически более низкими по сравнению с грудным конституциональным типом ( $<<0,01)$.

Таблицча 1.

\section{Структурно-функциональное состояние миокарда у лиц с артериальной} гипертонией различных конституциональных типов

\begin{tabular}{|c|c|c|c|c|}
\hline \multirow[b]{2}{*}{ Показатель } & \multicolumn{4}{|c|}{ Конституциональный тип } \\
\hline & 1. Брюшной & 2. Грудной & $\begin{array}{l}\text { 3. Мус- } \\
\text { кульный }\end{array}$ & $\begin{array}{l}\text { 4. Неопре- } \\
\text { деленный }\end{array}$ \\
\hline ДЛП, см & $3,85 \pm 0,08 * 1,2$ & $3,47 \pm 0,12 * 1,2$ & $3,68 \pm 0,13$ & $3,68 \pm 0,23$ \\
\hline ТЗСЛЖ, см & $1,14+0,03$ & $1,09 \pm 0,04$ & $1,18 \pm 0,06$ & $1,05 \pm 0,06$ \\
\hline ТМЖП, см & $1,3 \pm 0,05$ & $1,15 \pm 0,08$ & $1,2 \pm 0,07$ & $1,18 \pm 0,06$ \\
\hline Индекс ас. & $1,15 \pm 0,04$ & $1,07 \pm 0,08$ & $1,03 \pm 0,05$ & $1,13 \pm 0,06$ \\
\hline OTC, $\mathrm{cm}$ & $0,47 \pm 0,02$ & $0,43 \pm 0,02$ & $0,45 \pm 0,03$ & $0,40 \pm 0,02$ \\
\hline КДРЛЖ, см & $5,3 \pm 0,09$ & $5,2 \pm 0,08$ & $5,3 \pm 0,12$ & $5,6 \pm 0,29$ \\
\hline $\begin{array}{l}\text { ИКДРЛЖ, } \\
\mathrm{cm} / \mathrm{m}^{2}\end{array}$ & $2,59 \pm 0,05 * * 1,2 ; * * 1,4$ & $2,85 \pm 0,04 * * 1,2$ & $2,68 \pm 0,08 * 3,4$ & $3,04 \pm 0,14 * 3,4 ; * * 1,4$ \\
\hline КДО, мл & $145 \pm 6,6$ & $129,3 \pm 4,8$ & $137,2 \pm 6,7$ & $157,4 \pm 19,5$ \\
\hline ММЛЖ, г & $183,1 \pm 6,2$ & $163,9 \pm 8,1$ & $171,4 \pm 11,9$ & $180,5 \pm 19,2$ \\
\hline $\begin{array}{l}\text { ИММ ЛЖ, } \\
\Gamma / \mathrm{M}^{2}\end{array}$ & $89,3 \pm 3,1$ & $90,3 \pm 4,5$ & $85,9 \pm 5,5$ & $96,8 \pm 8,5$ \\
\hline$\Phi B, \%$ & $58,7 \pm 1,2 * 1,2$ & $64,6 \pm 1,7 * 1,2 ; * * 2,4$ & $60,3 \pm 1,3$ & $54,8 \pm 3,7 * * 2,4$ \\
\hline$\Phi C, \%$ & $31,7 \pm 0,9 * 1,2$ & $35,4 \pm 1,02 * 1,2 ; * * 2,4$ & $33,1 \pm 0,9$ & $29,7 \pm 2,2 * * 2,4$ \\
\hline Vcf, см/сек & $0,98 \pm 0,03 * 1,4$ & $1,11 \pm 0,04 * 2,4$ & $1,07 \pm 0,04 * 3,4$ & $0,90 \pm 0,08 * 1,4 ; * 2,4 ; * 3,4$ \\
\hline УО, мл & $82,4 \pm 3,4$ & $81,7 \pm 3,1$ & $80,8 \pm 3,9$ & $79,6 \pm 6,2$ \\
\hline МО, л/мин & $5,92 \pm 0,3$ & $6,12 \pm 0,2$ & $5,9 \pm 0,3$ & $6,03 \pm 0,6$ \\
\hline УИ, мл/ м $^{2}$ & $40,15 \pm 1,6$ & $44,9 \pm 1,6$ & $40,9 \pm 2,2$ & $43,12 \pm 3,2$ \\
\hline СИ, л/мин/м² & $2,88 \pm 0,13 * 1,2$ & $3,37 \pm 0,13 * 1,2$ & $2,99 \pm 0,18$ & $3,26 \pm 0,29$ \\
\hline $\begin{array}{l}\text { ОПСС, } \\
\text { дин }{ }^{*} \text { сек* }{ }^{-5}\end{array}$ & $1805 \pm 82,4$ & $1589 \pm 85,4$ & $1755 \pm 122,5$ & $1720 \pm 186,4$ \\
\hline
\end{tabular}

Примечание: Статистически значимые различия между группами - * $\mathrm{p}<0,05$; $* * \mathrm{p}<0,01$

При этом ФВ и ФС у больных АГ грудного соматотипа имели статистически значимо более высокие значения по сравнению с пациентами брюшного соматотипа ( $<0,05)$ (табл.1). При сравнении показателей ско- 
рости циркулярного сокращения волокон, у лиц неопределенного соматотипа изучаемый показатель также был статистически значимо меньше по сравнению с пациентами грудного, брюшного и мускульного соматотипов $(\mathrm{p}<0,05)$. При сравнении структурных показателей миокарда статистически значимые различия были получены только по значениям диаметра левого предсердия у представителей брюшного и грудного типов конституции $(\mathrm{p}<0,05)$ а по индексу конечно-диастолического размера левого желудочка (ИКДРЛЖ) между неопределенным и мускульным $(\mathrm{p}<0,05)$, неопределенным и брюшным ( $<<0,01)$ соматотипами и между грудным и брюшным ( $<<0,01)$ соматотипами соответственно. Следует отметить, что у лиц неопределенного соматотипа показатели как ИКДРЛЖ, так и величина конечно-диастолического размера (КДРЛЖ) левого желудочка имели наибольшие значения (табл.1).

Таким образом, резюмируя вышеизложенное следует отметить, что при сравнении структурно-функциональных показателей миокарда у больных АГ разных соматотипов можно отметить, что величина ФВ и ФС у больных АГ неопределенного соматотипа являются наименьшими и достоверно более низкими по сравнению с грудным $(\mathrm{p}<0,01)$, а показатели ФВ и ФС у лиц с АГ грудного соматотипа являются достоверно более высокими по сравнению с брюшным соматотипом $(\mathrm{p}<0,05)$. Следовательно, для лиц с АГ грудного соматотипа характерны более благоприятные значения некоторых структурно-функциональных показателей состояния миокарда, в сравнении с брюшным и неопределенным типами конституции.

Далее были определены типы гемодинамики и изучена их частота у мужчин с АГ и пациентов контрольной группы (рис. 1). Установлено, что гиперкинетический тип гемодинамики встречался у 44,4\% больных АГ (36 чел. из 81), эукинетический тип - у 42\% (34 чел. из 81) и гипокинетический тип - у 13,6\% (11 чел. из 81) (рис.1).

Гиперкинетический и эукинетический типы гемодинамики у больных АГ встречались чаще, по сравнению с лицами с гипокинетическим типом. Полученные данные несколько отличались от результатов исследования по изучению распределения типов центральной гемодинамики у мигрантов Крайнего Севера с АГ, прибывших на постоянное место жительства в центральную Сибирь. Так, среди мигрантов чаще выявлялся гипокинетический тип гемодинамики $66,7 \%$, реже гиперкинетический $-16,7 \%$ и эукинетический типы - 16,7\% соответственно [Деревянных Е.В., Яскевич Р.А. Изучение и сравнительный анализ показателей центральной гемодинамики и артериального давления у пожилых мигрантов Крайнего Севера 
с артериальной гипертензией // Клиническая геронтология. 2017. Т. 23. № 9-10. С. 23-25.]. По данным Терегулова Ю.Э. (2012) установлено, что гиперкинетический тип гемодинамики выявлялся у $3,2 \%$ пациентов, эукинетический - у 61,9\%, гипокинетический - в 34,9\% случаев [Терегулов Ю.Э. Интегральные показатели центральной гемодинамики у здоровых лиц и пациентов с гипертонической болезнью в зависимости от типа гемодинамики // Практическая медицина. 2012. № 8-2 (64). С. 164-168.]. Анализ новых случаев артериальной гипертонии за 4-летний период с учетом типов гемодинамического кровообращения у проживающих на Крайнем Севере показал, что трансформация нормального уровня АД в артериальную гипертонию отмечалась преимущественно у лиц с гиперкинетическим типом ( $<0,001)$ [Поликарпов Л.С., Хамнагадаев И.И., Яскевич Р.А., Деревянных Е.В. Артериальная гипертония (распространенность, профилактика, адаптация и реадаптация к различным экологическим условиям). Красноярск: КрасГМУ, 2010. 289 с.].

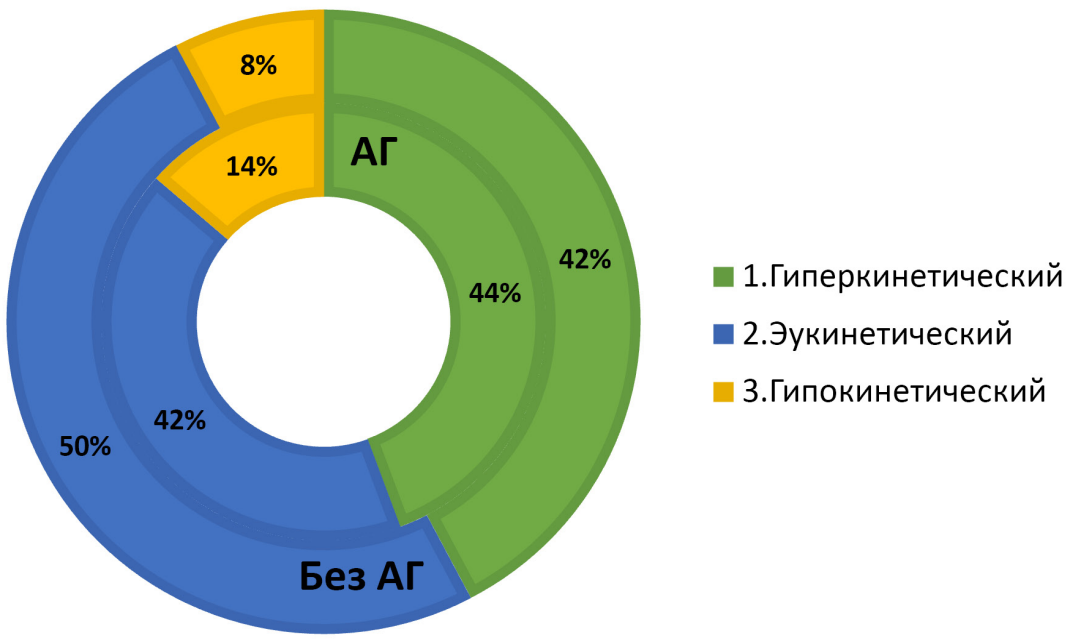

Рис. 1. Частота типов гемодинамики у мужчин с АГ и контрольной группы.

Примечание: Значимость различий между группами $\mathrm{p}_{1,3}<0,05 ; \mathrm{p}_{2,3}<0,05 ; \mathrm{p}_{1,2}>0,05$.

Частота типов гемодинамики среди пациентов контрольной группы имела схожие значения с частотой в основной группе. Так гиперкинетический тип гемодинамики встречался у 42,3\% (11 чел. из 26) обследованных, эукинетический тип - у 50\% (13 чел. из 26) и наиболее редко 
гипокинетический тип - у 7,7\% (2 чел. из 26) соответственно (рис.1). Таким образом эукинетический и гиперкинетический типы гемодинамики встречались в контрольной группе чаще по сравнению с гипокинетическим типом. По данным Поликарпова Л.С. со соавт. (2010) у лиц с нормальным уровнем артериального давления, проживающих в условиях Крайнего Севера, доминирует гиперкинетический тип гемодинамики, частота распределения которого достоверно отличается от эукинетического и гипокинетического [Поликарпов Л.С., Хамнагадаев И.И., Яскевич Р.А., Деревянных Е.В. Артериальная гипертония (распространенность, профилактика, адаптация и реадаптация к различным экологическим условиям). Красноярск: КрасГМУ, 2010. 289 с.].

Согласно результатов исследования Терегулова Ю.Э. (2012) в группе здоровых лиц выявлено 21,9\% с гиперкинетическим типом кровообращения, 65,6\% с эукинетическим и $12,5 \%$ с гипокинетическим [Терегулов Ю.Э. Интегральные показатели центральной гемодинамики у здоровых лиц и пациентов с гипертонической болезнью в зависимости от типа гемодинамики // Практическая медицина. 2012. № 8-2 (64). С. 164-168.].

При изучении частоты встречаемости типов гемодинамики у больных АГ различных конституциональных типов установлено, что гиперкинетический тип чаще отмечался среди лиц неопределенного - 75,0\%, грудного - у 60,0\%, и мускульного типов телосложения, в то время как у пациентов брюшного соматотипа чаще встречался гиперкинетический тип - 48,9\% (рис.2). Однако полученные различия в частоте типов гемодинамики не имели статистической значимости.

При сравнении частоты типов гемодинамики в группе контроля при различных соматотипах можно отметить, что при мускульном соматотипе гиперкинетический тип встречается реже, а эукинетический чаще по сравнению с грудным и брюшным соматотипами (рис.3).

У пациентов брюшного и грудного типа конституции чаще определялся гиперкинетический тип гемодинамики

Резюмируя вышеизложенное следует отметить, что пациенты грудного соматотипа в сравниваемых группах, по частоте типов гемодинамики различий не имели, тогда как среди больных с АГ при брюшном соматотипе чаще определялся эукинетический тип, а при мускульном - гиперкинетический. У пациентов без АГ, частота изучаемых типов гемодинамики (эукинетического и гиперкинетического) при данных соматотипах (брюшном и мускульном) была обратной. 


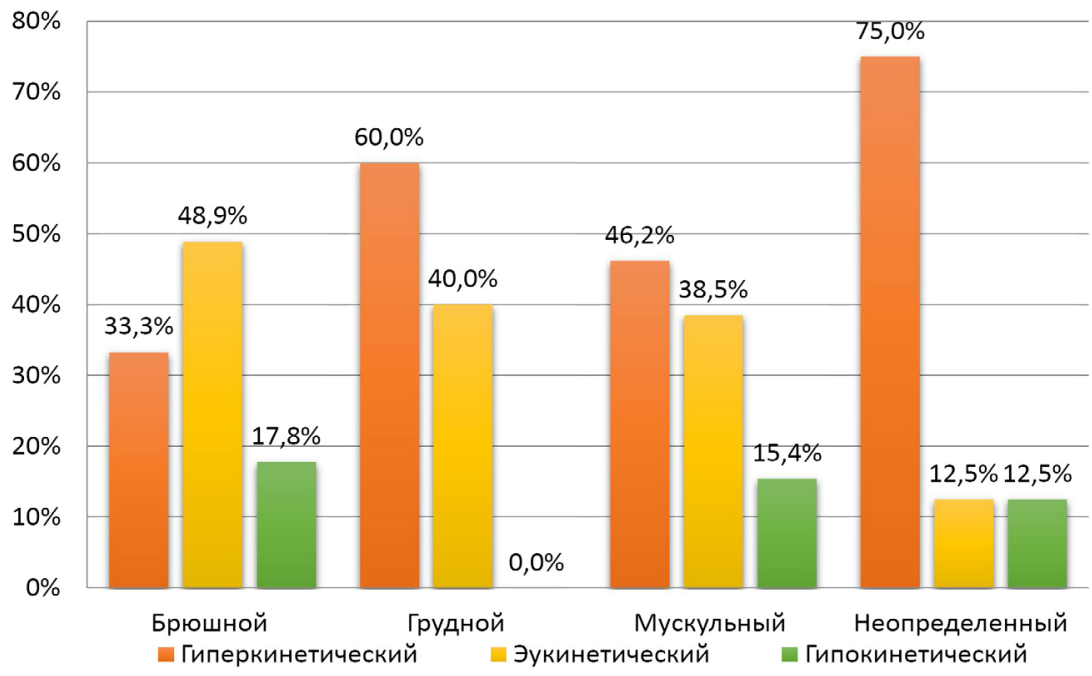

Рис. 2. Частота типов гемодинамики у больных с артериальной гипертонией различных конституциональных типов.

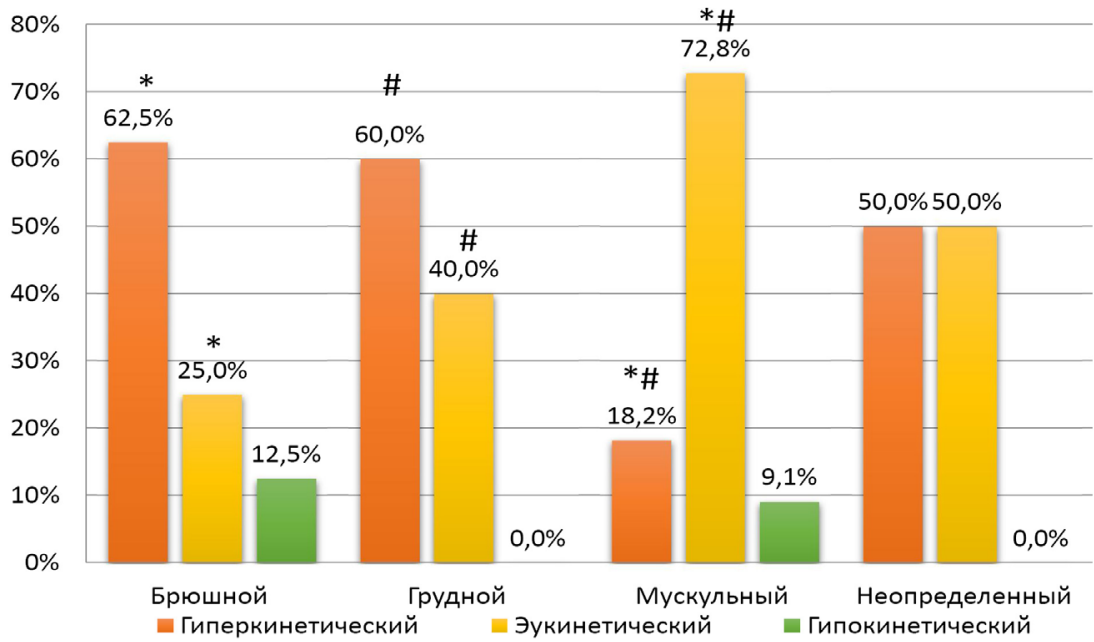

Рис. 3. Частота типов гемодинамики у пациентов контрольной группы различных конституциональных типов.

Примечание: Значимость различий между группами соматотипов $-{ }^{*} \mathrm{p}_{1-3}<0,05$; \#

$$
\mathrm{p}_{2-3}<0,05
$$




\section{Выводы}

1. В ходе проведённого исследования установлено, что как среди больных АГ, так и среди лиц без АГ, эукинетический и гиперкинетический типы гемодинамики встречаются чаще по сравнению с гипокинетическим типом.

2. При изучении частоты встречаемости типов гемодинамики у больных АГ с различными соматотипами не получено статистически значимо различий между группами, в то время как в группе контроля количество лиц с мускульным соматотипом была статистически значимо выше при эукинетическом типе гемодинамики, и ниже при гиперкинетическом типе в сравнении с грудным и брюшным соматотипами.

3. При сравнении структурно-функциональных показателей миокарда у больных АГ разных соматотипов можно отметить, что величина фракции выброса и фракции сокращения у больных АГ неопределенного соматотипа были наименьшими и статистически значимо более низкими по сравнению с грудным типом телосложения $(\mathrm{p}<0,01)$, а у лиц с АГ грудного соматотипа статистически значимо более высокими по сравнению с брюшным конституциональным типом $(\mathrm{p}<0,05)$.

\section{Список литературы}

1. Антонов А.А. Гемодинамика при гипертонической болезни // Поликлиника. 2013. № 4-2. С. 36-41.

2. Василькова Т.Н., Баклаева Т.Б., Матаев С.И. Рыбина Ю.А. Влияние различных типов жироотложения на состояние сердечно-сосудистой системы // Сердце: журнал для практикующих врачей. 2014. Т.75, №1. С. 45-49.

3. Давыдов Е.Л., Ульянова И.О. Медико-социальные аспекты больных артериальной гипертонией в пожилом возрасте // Клиническая геронтология. 2016. Т. 22, № 9-10. С. 24-25.

4. Деревянных Е.В., Яскевич Р.А., Балашова Н.А. Антропометрические особенности и компонентный состав массы тела у мужчин медицинских работников с артериальной гипертонией // Международный журнал прикладных и фундаментальных исследований. 2016. № 6-2. С. 252-256.

5. Деревянных Е.В., Яскевич Р.А., Балашова Н.А. Возрастные особенности приверженности к лечению артериальной гипертонии у мужчин г. Красноярска // Международный журнал прикладных и фундаментальных исследований. 2016. № 6-1. С. 48-52.

6. Деревянных Е.В., Яскевич Р.А. Изучение и сравнительный анализ показателей центральной гемодинамики и артериального давления у пожилых 
мигрантов Крайнего Севера с артериальной гипертензией // Клиническая геронтология. 2017. Т. 23. № 9-10. С. 23-25.

7. Кандилова В.Н. Ремоделирование сердца и сосудов при артериальной гипертензии: роль сопутствующего ожирения // Клиницист. 2020. Т. 14, № 1-2. C. 62-72.

8. Кедринская А.Г., Куприенко Н.Б., Образцова Г.И., Леонова И.А. Структурные изменения сердца и антропометрические маркеры ремоделирования миокарда при избыточной массе тела и ожирении у детей // Артериальная гипертензия. 2018. Т. 24, № 5. С.570-580

9. Клеменков А.С., Фурсова Я.Е., Клеменков С.В. и др. Влияние общих пресных ванн и физических тренировок при разной длительности назначения на физическую работоспособность больных стабильной стенокардией с нарушением ритма // Фундаментальные исследования. 2006. № 3. С. 13.

10. Козлов Е.В., Яскевич Р.А., Москаленко О.Л., Кочергина К.Н. Антропометрические особенности и компонентный состав массы тела у мужчин с хронической обструктивной болезнью легких в условиях коморбидности // Siberian Journal of Life Sciences and Agriculture. 2019. T. 11. № 4. C. 56-73.

11. Москаленко О.Л. Характеристика свойств темперамента у юношей-студентов разных соматотипов г. Железногорска // В мире научных открытий. 2015. № 8.1 (68). С. 442-449.

12. Никитюк Д.Б., Николенко В.Н., Хайруллин Р.М. и др. Антропометрический метод и клиническая медицина // Журнал анатомии и гистопатологии. 2013. T. 2, № 2. С. 10-14.

13. Поликарпов Л.С., Хамнагадаев И.И., Яскевич Р.А., Деревянных Е.В. Артериальная гипертония (распространенность, профилактика, адаптация и реадаптация к различным экологическим условиям). Красноярск: КрасГМУ, 2010. 289 c.

14. Терегулов Ю.Э. Интегральные показатели центральной гемодинамики у здоровых лиц и пациентов с гипертонической болезнью в зависимости от типа гемодинамики // Практическая медицина. 2012. № 8-2 (64). С. $164-168$.

15. Халявкина И.О. Индивидуально-типологические особенности гемодинамики в юношеском возрасте // Журнал фундаментальной медицины и биологии. 2017. №1. С. 38-44.

16. Шалауров А.В., Кочетова Н.В., Додонова Л.П., Щедрин А.С. Соматотип и основные показатели деятельности сердечно-сосудистой системы в покое и при физической нагрузке // Новости спортивной и медицинской антропологии. М., 1990. Вып. 1. С.163. 
17. Яскевич Р.А., Деревянных Е.В., Балашова Н.А. Использование показателей соматотипирования у мужчин в построении математических моделей прогноза развития артериальной гипертонии // Международный журнал прикладных и фундаментальных исследований. 2015. № 1-1. С. 64-69.

18. Яскевич Р.А., Повшедная О.Н., Деревянных Е.В. Нарушения ритма сердца у мужчин, жителей Сибири, с артериальной гипертонией различных конституциональных типов // Успехи современного естествознания. 2015. № 3. C. $127-132$.

19. Яскевич Р.А., Москаленко О.Л. Антропометрические особенности и компонентный состав массы тела у мужчин мигрантов Крайнего Севера с артериальной гипертонией // В мире научных открытий. 2016. № 10 (82). С. 10-34.

20. Britton K.A., Massaro J.M., Murabito J.M. et al. Body fat distribution, incident cardiovascular disease, cancer, and all-cause mortality // J. Am. Coll. Cardiol. 2013. Vol. 62, N.10. P.921-925.

21. Kim N.Y., Hong Y.M., Jung J.W. et al. The relationships of body mass index, waist-to-height ratio, and body fat percentage with blood pressure and its hemodynamic determinants in Korean adolescents: a school-based study // Korean J. Pediatr. 2013. Vol. 56, N 12. P. 526-533.

22. Nichols M., Townsend N., Scarborough P., Rayner M. Cardiovascular disease in Europe: epidemiological update // Eur. Heart J. 2013. Vol.34. P. 3028-3034.

23. Polikarpov L.S., Yaskevich R.A., Derevyannich E.V. et al. Readaptation of patients with arterial hypertension long-term residents of the Far North to new climatic conditions // International Journal of Circumpolar Health. 2012. Vol. 72, S 1. P. 337-339.

24. Selvaraj S., Martinez E.E., Aguilar F.G. et al. Association of central adiposity with adverse cardiac mechanics: findings from the HyperGEN Study // Circ. Cardiovasc. Imaging. 2016. Vol. 9, N 6. P. e004396.

25. Williams B., Mancia G., Spiering W. et al; ESC Scientific Document Group. 2018 ESC/ESH Guidelines for the management of arterial hypertension. The Task Force for the management of arterial hypertension of the European Society of Cardiology (ESC) and the European Society of Hypertension (ESH) // European Heart Journal. 2018. Vol. 39, N 33. P. 3021-104.

\section{References}

1. Antonov A.A. Gemodinamika pri gipertonicheskoj bolezni [Hemodynamics in hypertensive disease]. Poliklinika [Polyclinic]. 2013. № 4-2. P. 36-41.

2. Vasil'kova T.N., Baklaeva T.B., Mataev S.I. Rybina Ju. A. Vlijanie razlichnyh tipov zhirootlozhenija na sostojanie serdechno-sosudistoj sistemy [Influence 
of different types of fat deposition on the state of the cardiovascular system]. Serdce: zhurnal dlja praktikujushhih vrachej [Heart: a journal for practicing doctors]. 2014. V.75. №1. P. 45-49.

3. Davydov E.L., Ul'janova I.O. Mediko-social'nye aspekty bol'nyh arterial'noj gipertoniej v pozhilom vozraste [Medical and social aspects of patients with arterial hypertension in old age]. Klinicheskaja gerontologija [Clinical gerontology]. 2016. V. 22. № 9-10. P. 24-25.

4. Derevjannyh E.V., Jaskevich R.A., Balashova N.A. Antropometricheskie osobennosti i komponentnyj sostav massy tela u muzhchin medicinskih rabotnikov $\mathrm{s}$ arterial'noj gipertoniej [Anthropometric features and component composition of body weight in male medical workers with arterial hypertension]. Mezhdunarodnyj zhurnal prikladnyh i fundamental'nyh issledovanij [International Journal of Applied and Fundamental Research]. 2016. № 6-2. P. 252-256.

5. Derevjannyh E.V., Jaskevich R.A., Balashova N.A. Vozrastnye osobennosti priverzhennosti k lecheniju arterial'noj gipertonii u muzhchin g. Krasnojarska [Age characteristics of adherence to the treatment of arterial hypertension in men of Krasnoyarsk]. Mezhdunarodnyj zhurnal prikladnyh i fundamental'nyh issledovanij [International Journal of Applied and Fundamental Research]. 2016. № 6-1. P. 48-52.

6. Derevjannyh E.V., Jaskevich R.A. Izuchenie i sravnitel'nyj analiz pokazatelej central'noj gemodinamiki i arterial'nogo davlenija u pozhilyh migrantov Krajnego Severa s arterial'noj gipertenziej [Study and comparative analysis of indicators of central hemodynamics and blood pressure in elderly migrants of the Far North with arterial hypertension]. Klinicheskaja gerontologija [Clinical Gerontology]. 2017. V. 23. № 9-10. P. 23-25.

7. Kandilova V.N. Remodelirovanie serdca i sosudov pri arterial'noj gipertenzii: rol' soputstvujushhego ozhirenija [Remodeling of the heart and blood vessels in arterial hypertension: the role of concomitant obesity]. Klinicist [Clinician]. 2020. V. 14. № 1-2. P. 62-72.

8. Kedrinskaja A.G., Kuprienko N.B., Obrazcova G.I., Leonova I.A. Strukturnye izmenenija serdca i antropometricheskie markery remodelirovanija miokarda pri izbytochnoj masse tela i ozhirenii u detej [Structural changes in the heart and anthropometric markers of myocardial remodeling in overweight and obesity in children]. Arterial'naja gipertenzija [Arterial hypertension]. 2018. V. 24. № 5. P. 570-580.

9. Klemenkov A.S., Fursova Ja.E., Klemenkov S.V. i dr. Vlijanie obshhih presnyh vann i fizicheskih trenirovok pri raznoj dlitel'nosti naznachenija na fizicheskuju rabotosposobnost' bol'nyh stabil'noj stenokardiej s narusheniem ritma 
[Influence of general fresh baths and physical training with different duration of appointment on the physical performance of patients with stable angina pectoris with rhythm disturbances]. Fundamental'nye issledovanija [Fundamental research]. 2006. № 3. Р. 13.

10. Kozlov E.V., Jaskevich R.A., Moskalenko O.L., Kochergina K.N. Antropometricheskie osobennosti i komponentnyj sostav massy tela u muzhchin s hronicheskoj obstruktivnoj bolezn'ju legkih v uslovijah komorbidnosti [Anthropometric features and component composition of body weight in men with chronic obstructive pulmonary disease in conditions of comorbidity]. Siberian Journal of Life Sciences and Agriculture. 2019. V. 11. № 4. P. 56-73.

11. Moskalenko O.L. Harakteristika svojstv temperamenta u junoshej-studentov raznyh somatotipov g. Zheleznogorska [Characteristics of the properties of temperament in young men-students of different somatotypes of Zheleznogorsk]. V mire nauchnyh otkrytij [In the world of scientific discoveries]. 2015. № 8.1 (68). P. 442-449.

12. Nikitjuk D.B., Nikolenko V.N., Hajrullin R.M. i dr. Antropometricheskij metod i klinicheskaja medicina [Anthropometric method and clinical medicine]. Zhurnal anatomii i gistopatologii [Journal of anatomy and histopathology]. 2013. V. 2. № 2. P. 10-14.

13. Polikarpov L.S., Hamnagadaev I.I., Jaskevich R.A., Derevjannyh E. V. Arterial'naja gipertonija (rasprostranennost', profilaktika, adaptacija i readaptacija k razlichnym jekologicheskim uslovijam) [Arterial hypertension (prevalence, prevention, adaptation and readaptation to various environmental conditions)]. Krasnojarsk: KrasGMU. 2010. 289 p.

14. Teregulov Ju.Je. Integral'nye pokazateli central'noj gemodinamiki u zdorovyh lic i pacientov s gipertonicheskoj bolezn'ju v zavisimosti ot tipa gemodinamiki [Integral indicators of central hemodynamics in healthy individuals and patients with essential hypertension depending on the type of hemodynamics]. Prakticheskaja medicina [Practical medicine]. 2012. № 8-2(64). P. 164-168.

15. Haljavkina I.O. Individual'no-tipologicheskie osobennosti gemodinamiki v junosheskom vozraste [Individual-typological characteristics of hemodynamics in adolescence]. Zhurnal fundamental'noj mediciny $i$ biologii [Journal of fundamental medicine and biology]. 2017. №1. P. 38-44.

16. Shalaurov A.V., Kochetova N.V., Dodonova L.P., Shhedrin A.S. Somatotip i osnovnye pokazateli dejatel'nosti serdechno-sosudistoj sistemy v pokoe i pri fizicheskoj nagruzke [Somatotype and the main indicators of the cardiovascular system at rest and during exercise]. Novosti sportivnoj i medicinskoj antropologii [News of sports and medical anthropology]. M., 1990. Issue 1. P.163. 
17. Jaskevich R.A., Derevjannyh E.V., Balashova N.A. Ispol'zovanie pokazatelej somatotipirovanija u muzhchin $\mathrm{v}$ postroenii matematicheskih modelej prognoza razvitija arterial'noj gipertonii [The use of somatotyping indicators in men in the construction of mathematical models for predicting the development of arterial hypertension]. Mezhdunarodnyj zhurnal prikladnyh i fundamental'nyh issledovanij [International Journal of Applied and Fundamental Research]. 2015. № 1-1. P. 64-69.

18. Jaskevich R.A., Povshednaja O.N., Derevjannyh E.V. Narushenija ritma serdca u muzhchin, zhitelej Sibiri, s arterial'noj gipertoniej razlichnyh konstitucional'nyh tipov [Heart rhythm disturbances in men, inhabitants of Siberia, with arterial hypertension of various constitutional types]. Uspehi sovremennogo estestvoznanija [Successes of modern natural science]. 2015. № 3. P. 127-132.

19. Jaskevich R.A., Moskalenko O.L. Antropometricheskie osobennosti i komponentnyj sostav massy tela u muzhchin migrantov Krajnego Severa s arterial'noj gipertoniej [Anthropometric features and component composition of body weight in male migrants of the Far North with arterial hypertension]. V mire nauchnyh otkrytij [In the world of scientific discoveries]. 2016. № 10(82). P. 10-34.

20. Britton K.A., Massaro J.M., Murabito J.M. et al. Body fat distribution, incident cardiovascular disease, cancer, and all-cause mortality. J. Am. Coll. Cardiol. 2013. Vol. 62. N.10. P.921-925.

21. Kim N.Y., Hong Y.M., Jung J.W. et al. The relationships of body mass index, waist-to-height ratio, and body fat percentage with blood pressure and its hemodynamic determinants in Korean adolescents: a school-based study. Korean J. Pediatr. 2013. Vol. 56. N12. P. 526-533.

22. Nichols M., Townsend N., Scarborough P., Rayner M. Cardiovascular disease in Europe: epidemiological update. Eur. Heart J. 2013. Vol.34. P. 3028-3034.

23. Polikarpov L.S., Yaskevich R.A., Derevyannich E.V. et al. Readaptation of patients with arterial hypertension long-term residents of the Far North to new climatic conditions. International Journal of Circumpolar Health. 2012. Vol. 72. S1. P. 337-339.

24. Selvaraj S., Martinez E.E., Aguilar F.G. et al. Association of central adiposity with adverse cardiac mechanics: findings from the HyperGEN Study. Circ. Cardiovasc. Imaging. 2016. Vol. 9. N 6. P. e004396.

25. Williams B., Mancia G., Spiering W. et al; ESC Scientific Document Group. 2018 ESC/ESH Guidelines for the management of arterial hypertension. The Task Force for the management of arterial hypertension of the European Society of Cardiology (ESC) and the European Society of Hypertension (ESH). European Heart Journal. 2018. Vol. 39.N 33. P. 3021-104. 


\section{ДАННЫЕ ОБ АВТОРАХ}

Яскевич Роман Анатольевич, доцент кафедры пропедевтики внутренних болезней и терапии, ведущий научный сотрудник группы патологии сердечно-сосудистой системы, кандидат медицинских наук, доцент Федеральное государственное бюджетное научное учреждение «Научно-исследовательский институт медицинских проблем Севера»; ФГБОУ ВО КрасГМУ им. проф. В.Ф. Войно-Ясенечкого Минздрава России

ул. Партизана Железняка, 32, г. Красноярск, 660022, Российская Федерачия; ул. Партизана Железняка, 1а, г. Красноярск, 660022, Российская Федерачия

cardio@impn.ru

Повшедная Оксана Николаевна, врач-терапевт, кандидат медицинских наук

Краевое государственное бюджетное учреждение здравоохранения "Красноярская межрайонная больнииа № 3"

ул. Свердловская, 76, Красноярск, 660006, Российская Федерачия krasmb3@yandex.ru

Москаленко Ольга Леонидовна, старший научный сотрудник, кандидат биологических наук

Федеральное государственное бюджетное научное учреждение «Научно-исследовательский институт медииинских проблем Севера» ул. Партизана Железняка, 32, г. Красноярск, 660022, Российская Федерация

gre-ll@mail.ru

\section{DATA ABOUT THE AUTHORS}

Yaskevich Roman Anatolyevich, Associate Professor at Department of Propedeutics of Internal Diseases and Therapy, Leading Researcher of the Group Pathology of the Cardiovascular System, Candidate of Medical Science, Docent

Scientific Research Institute of medical problems of the North; Krasnoyarsk State Medical University named after Professor V.F. VoinoYasenetzkiy

3g, P. Zheleznyaka St., Krasnoyarsk, 660022, Russian Federation; 1a, P. Zheleznyaka St., Krasnoyarsk, 660022, Russian Federation cardio@impn.ru 
Povshednaya Oksana Nikolaevna, Therapist, Candidate of Medical Science Krasnoyarsk inter-district hospital № 3

76, Sverdlovskaja St., Krasnoyarsk, 660006, Russian Federation krasmb3@yandex.ru

Moskalenko Olga Leonidovna, Senior Researcher, Candidate of Biological Sciences

Scientific Research Institute of medical problems of the North 3g, P. Zheleznyaka St., Krasnoyarsk, 660022, Russian Federation gre-ll@mail.ru 